\title{
Pigments and binding media of polychrome relics from the central hall of Longju temple in Sichuan, China
}

\author{
Erxin Chen ${ }^{1}$, Bingjian Zhang ${ }^{1,2^{*} \mathbb{D}}$, Fan Zhao ${ }^{3}$ and Chong Wang ${ }^{3}$
}

\begin{abstract}
Longju temple, located in Guanghan County, Sichuan province of China, is a Buddhist temple with great cultural significance. It has preserved polychrome relics since 1466 of the Ming dynasty. The deterioration of these ancient colored paintings is posing an extremely serious issue, it is exceptionally critical to propose an appropriate protection plan. In this paper, pigments and binding media were analyzed from ten polychrome samples collected from the central hall of Longju temple. A series of analysis methods were adopted, including the Raman spectrum, scanning electron microscopy-energy disperse spectrometer (EDS-SEM), and enzyme-linked immunosorbent assay (ELISA). Results demonstrate the existence of atacamite, azurite, carbon black, cinnabar, and gold in the color layer of the samples. Egg white, animal glue, and casein were found to be used as binders in the colored paintings. This study not only offered essential data for the follow-up protection and repair projects but also provided a reference to further explore the polychrome relics of other Buddhist temples in the Ming dynasty of China.
\end{abstract}

Keywords: Polychrome relics, Colored paintings, Pigment, Raman, SEM-EDS, ELISA

\section{Introduction}

Sichuan province, a prevailing Buddhist region in ancient China, has once developed a distinctive and unique art style of wall and board paintings in history. Unfortunately, due to the warmth, humidity and rainy climate in this region, the murals and wood paintings of Buddhist temples in the Ming dynasty (1368AD-1644AD) are extremely rare nowadays [1]. With few of the ancient paintings remain, the remaining precious cultural relics are suffering from various kinds of erosions and degenerations, which will destroy the whole of the relics soon if no appropriate protective and repair measures are taken.

The Longju temple is one of the survived relics in the Ming dynasty and enjoys a high reputation among Buddhists in Sichuan. It is located in Longju village of Guanghan county and is $23 \mathrm{~km}$ away from the central Chengdu (as shown in Fig. 1a). It is a Buddhist building

\footnotetext{
*Correspondence: zhangbiji@zju.edu.cn

${ }^{1}$ Department of Cultural Heritage and Museology, Zhejiang University,

Hangzhou 310028, Zhejiang, People's Republic of China

Full list of author information is available at the end of the article
}

with wooden structures (as shown in Fig. 1b). The Longju temple was first constructed in the twelfth year of the Ming Orthodoxy Period (i.e., 1447 AD) [2, 3] and was dismantled and rebuilt during the 1950s. Nowadays, only the central hall of the temple remains as a heritage from the Ming dynasty, which became a national cultural relic in 2013.

The total area of the polychrome relics inside the central hall of the Longju temple is approximately $99.44 \mathrm{~m}^{2}$. According to the inscriptions, the polychrome relics date back to the second year of the Ming Chenghua period (i.e., $1466 \mathrm{AD}$ ). These masterpieces were drawn meticulously by the top artists in the local area, and lively presented the scenes of 12 Bodhisattvas of Perfect Enlightenment. The paintings adopted Chinese traditional painting skills of exact delineation and heavy colors and partially decorated with gold to enhance the brightness and magnificence. A representative painting is shown in Fig. 1c.

In order to better preserve these polychrome relics in a timely manner, it is essential to identify the main ingredients of the paintings, especially pigments and binders. 

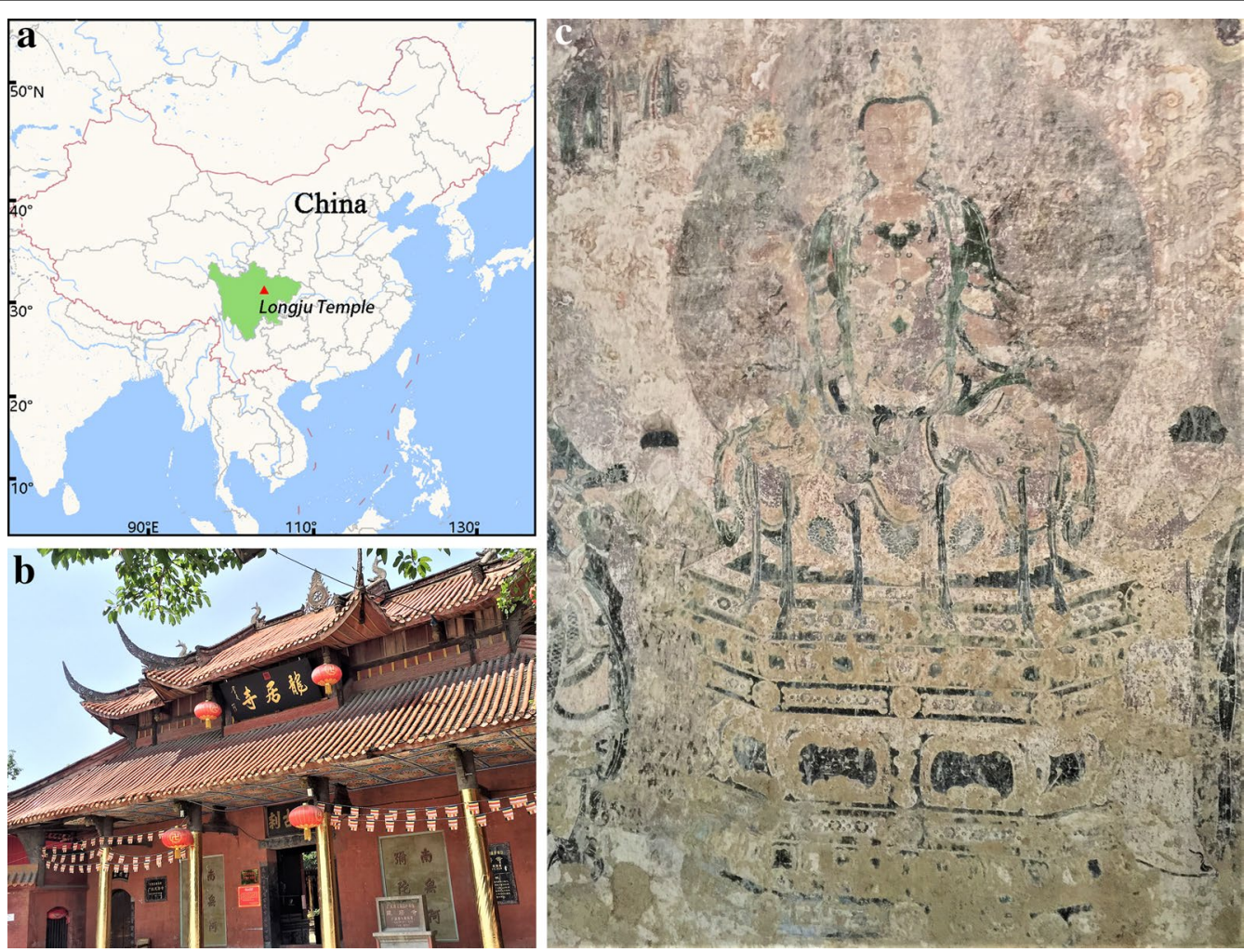

Fig. 1 Brief information of the Longju temple in Sichuan, China: a Geographical map of the Longju temple, $\mathbf{b}$ the facade of the Longju temple, c a representative photograph of the painted relics shot from the central hall of the Longju temple

Moreover, binders applied in different regions have different characteristics. It might be possible to infer the influence of Tibetan Buddhist in the Sichuan region through the binders' results of the Longju temple, for Sichuan province borders the Tibetan area.

Minimal amounts of samples were collected from the Longju temple and analyzed using a comprehensive method in the laboratory, including the Raman spectrum, scanning electron microscopy-energy disperse spectrometer (SEM-EDS) and enzyme-linked immunosorbent assay (ELISA). Raman spectroscopy can nondestructively identify the composition of pigments [4-6]. SEM-EDS assists in observing the surface morphology of samples and obtaining element content $[7,8]$, which further confirms the chemical composition of the samples.

The detection of binding media is challenging due to the low content of binders, many impurities, and protein degradation. Determining the binding media accurately by conventional instrumental analysis can be challenging. A useful technique, ELISA, was used in this study to detect specific proteins through antigen-antibody reaction with low sample consumption and high sensitivity. It is suitable for the detection of binding media in paintings [9-11]. The mammalian collagen, chicken ovalbumin, and casein were selected as target antigens to detect animal glue, egg white, and casein, respectively. After adding the primary and the enzyme-labeled antibody, the existence of corresponding target proteins will be proved if the coloring enzymatic reaction demonstrates significant color change.

\section{Aim of the study}

The aim of the study is to clarify the main ingredients of pigments and binding media. Multiple methods were adopted during the study, including instrumental analysis and biological detection techniques.

\section{Samples and methods Samples}

Ten fragments were carefully obtained from the walls, the cushion boards and the architraves in the central hall of the Longju temple. The paintings on the walls were drawn on a traditional ground layer and a lime layer. The paintings of the cushion boards and the architraves were both painted on the surface of the lime layer supported by wooden boards. To minimize the damage towards the relics, tiny fragments from the painting layer were scraped gently with a scalpel on the warped disease parts. 
The sample size did not exceed $10 \mathrm{~mm}^{2}$. More details of the samples are listed in Table 1.

Green and aureate colored samples were collected since they were the dominant colors in the paintings in Longju temple. The green samples, i.e., LJ01, LJ02 and LJ03 were collected from the wall, the architrave and the cushion board, respectively. LJ08, LJ09 and LJ10 were aureate, two from the walls and one from the architrave. In addition, a small amount of blue, black and red samples was collected since they appeared in the paintings. LJ04 and LJ05 were collected from different walls, LJ04 appears blue and LJ05 appears black. The red samples LJ06 and LJ07 were obtained from the architrave and the cushion board, respectively.

\section{Methods}

A comprehensive analysis was performed on the samples, which consisted of four methods: microscope, Raman spectrum, SEM-EDS and ELISA. During the testing process, ten samples were observed and photographed by a microscope. Then a Raman spectrometer was used to identify the ingredients of pigments. The element compositions of the samples were determined by SEM-EDS

Table 1 Details of samples from the central hall of the Longju temple

\begin{tabular}{|c|c|c|c|c|}
\hline Number & Surface color & Sample position & Sampling photograph & Macro image \\
\hline LJ01 & Green & Wall (east) & & \\
\hline LJ02 & Green & Architrave (west) & & \\
\hline LJ03 & Green & Cushion board (east) & & \\
\hline LJ04 & Blue & Wall (north) & & \\
\hline LJ05 & Black & Wall (west) & & \\
\hline LJ06 & Red & Architrave (west) & & \\
\hline LJ07 & Red & Cushion board (east) & & \\
\hline LJ08 & Aureate & Wall (east) & & \\
\hline LJ09 & Aureate & Architrave (west) & & \\
\hline LJ10 & Aureate & Wall (west) & & \\
\hline
\end{tabular}


to verify the results of Raman. Finally, ELISA was carried out to detect antibodies in the samples.

\section{Microscopy}

A Keyence VHX-700FC digital microscope with a VHZ100R objective was used to observe the samples. The macro images were photographed using the function of image mosaic.

\section{Raman spectroscopy}

The Raman spectra of ten samples were recorded with a LabRAM HR Evolution Confocal Microprobe Raman Spectroscopy equipped with an Olympus BX41 microscope.

The detection was conducted after calibration with a standard silicon slice. The colored area on the sample surface was observed using a $50 \times$ objective. The acquisition times and scanning times were adjusted with a range from 50 to 3000 wavenumbers. The red and black samples were excited by a $785 \mathrm{~nm}$ laser source, the green and blue ones were detected under a $532 \mathrm{~nm}$ laser. The Raman curves were then compared with the standard references acquired from the RRUFF database [12-14].

\section{SEM-EDS analysis}

The SEM-EDS analysis was carried out using a Hitachi TM3000 scanning electron microscope with a Quantax70 energy dispersive spectroscopy. The back-scattering mode was used with a voltage of $15 \mathrm{kV}$. Each sample was scanned at least three times for calculating the average element content.

\section{ELISA analysis}

A small amount of each sample was collected and ground with $1 \mu \mathrm{l}$ of carbonate buffer solution. The mixture was centrifuged, and then the supernatant was collected and placed on an ELISA well plate (50 $\mu \mathrm{l}$ to each plate). The plate was incubated at $4{ }^{\circ} \mathrm{C}$ for $12 \mathrm{~h}$. Then, the blocking solution, the primary antibodies, and the enzyme-labeled secondary antibody were added in order. Finally, a coloring enzymatic reaction was carried out [15]. Three primary antibodies were used in this experiment, i.e., rabbit polyclonal antibody to ovalbumin (Sigma-Aldrich, cod. C6534, diluted 1:1000), rabbit polyclonal antibody to collagen type I (Millipore, cod. AB749P, diluted 1:5000), and rabbit polyclonal antibody to casein (Abcam, cod. AB166596, diluted 1:5000). The goat anti-rabbit IgG conjugated enzyme alkaline phosphatase purchased from Google Biology was used as an enzyme-labeled antibody, it was diluted with phosphate-buffered saline to the concentration of 1:5000.

In order to quantitatively measure the positive degree of the test results, the absorbance values at $\mathrm{OD}_{450 \mathrm{~nm}}$ and $\mathrm{OD}_{630 \mathrm{~nm}}$ of the ELISA well plate were collected by an R-Biopharm WELL Reader (an enzyme micro-plate reader). The $\mathrm{OD}$ value was obtained by subtracting the values of $\mathrm{OD}_{630 \mathrm{~nm}}$ from $\mathrm{OD}_{450 \mathrm{~nm}}$. Each sample was tested in triplicates, and the results were averaged.

\section{Results and discussions Pigment analysis}

The results of the Raman and SEM-EDS are presented in Table 2 and discussed below.

\section{Green}

The Raman characteristic curves of the green samples are shown in Fig. 2. The strong peaks of the wavenumber are near 3350 and $3436 \mathrm{~cm}^{-1}$, which correspond to those in the atacamite reference. The element composition of each sample was determined by SEM-EDS (see Table 2). The mass percentages of $\mathrm{Cu}$ in LJ01, LJ02 and LJ03 are

Table 2 Summary table of analysis results of main coloring pigment and organic binding media

\begin{tabular}{|c|c|c|c|c|c|}
\hline Number & Surface colors & Substrate & $\begin{array}{l}\text { Main coloring } \\
\text { pigment (chemical } \\
\text { formula) }\end{array}$ & Main element content characterized by EDS (wt\%) & Organic binding media \\
\hline LJ01 & Green & Wall & Atacamite $\left(\mathrm{Cu}_{2}(\mathrm{OH})_{3} \mathrm{Cl}\right)$ & O (59.7), Ca (16.9), S (14.3), C (7.0), Cu (1.4) & Animal glue \\
\hline LJ02 & & Wood & Atacamite $\left(\mathrm{Cu}_{2}(\mathrm{OH})_{3} \mathrm{Cl}\right)$ & O (37.6), Cu (25.5), S (23.6), C (7.4) & Casein \\
\hline LJ03 & & Wood & Atacamite $\left(\mathrm{Cu}_{2}(\mathrm{OH})_{3} \mathrm{Cl}\right)$ & O (41.3), C (29.1), Ca (8.7), S (8.3), Si (4.7), Cu (3.2) & Negative \\
\hline LJ04 & Blue & Wall & Azurite $\left(\mathrm{Cu}_{2}(\mathrm{OH})_{2} \mathrm{CO}_{3}\right)$ & O (44.8), C (26.9), Cu (6.5), Ca (6.0), S (5.7), Si (4.9) & Egg white \\
\hline LJ05 & Black & Wall & Carbon black (C) & $\mathrm{O}(38.1), \mathrm{C}(33.0), \mathrm{Ca}(8.6), \mathrm{Pb}(7.2), \mathrm{Si}(4.5)$ & Negative \\
\hline LJ06 & Red & Wood & Cinnabar (HgS) & $\mathrm{C}(40.9), \mathrm{O}(27.0), \mathrm{S}(13.0), \mathrm{Hg}(6.8)$ & Negative \\
\hline LJ07 & & Wood & Cinnabar (HgS) & C (35.0), O (31.0), Hg (19.4), S (4.0), Si (3.2), Ca (3.1) & Egg white, animal glue \\
\hline LJ08 & Aureate & Wall & Gold $(\mathrm{Au})$ & C (39.2), O (27.5), Au (10.9), S (9.1), Si (4.1), Ca (3.2) & Animal glue \\
\hline LJ09 & & Wood & Gold (Au) & C (46.8), O (27.0), S (6.9), Si (4.9), Ca (4.0), Au (3.9) & Animal glue \\
\hline LJ10 & & Wall & Gold (Au) & C (34.8), O (24.7), Pb (11.1), Au (10.8), Si (4.6), Ca (4.2), S (3.0) & Animal glue \\
\hline
\end{tabular}




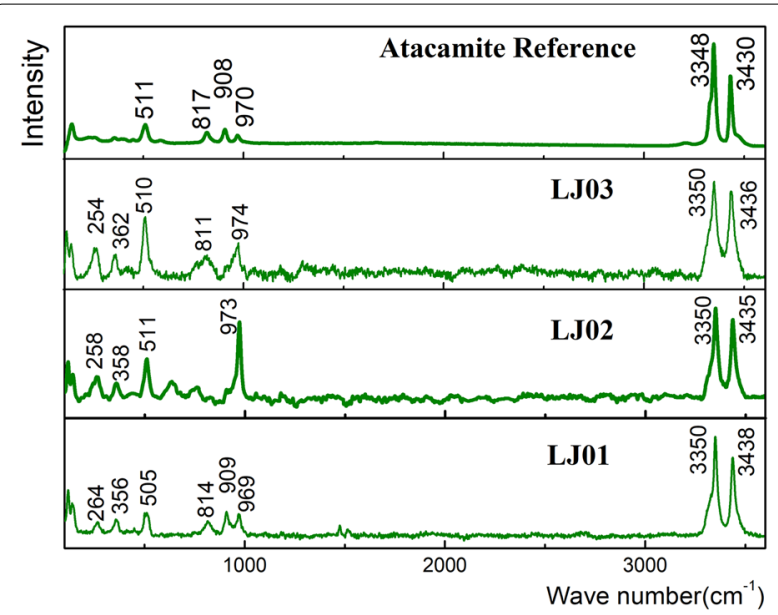

Fig. 2 Raman spectra of LJ01, LJ02, LJ03 and atacamite reference

$1.4 \%, 25.5 \%$ and $3.2 \%$, respectively. It reveals the presence of atacamite in the green pigments.

Atacamite is the main representative of copper green pigments, which was widely used in ancient Chinese murals after the Northern dynasty due to the advancement of synthetic technology $[16,17]$. Natural copper green ore resources are very scarce in China; it has only been found in the Kangjiltag gold deposit in Xinjiang province [18]. Thus, it is speculated that the atacamite in Longju temple is more likely to be a non-natural pigment.

As shown in Table 2, the content of copper in LJ01 is low, while that of calcium and sulfur are relatively high. In addition, $3.6 \mathrm{wt} \%$ calcium was found in the bottom layer of LJ01. It can be inferred that the base layer of LJ01 does contain calcium, and most of the calcium had migrated to the surface of the sample. The sulfur may come from sulfur gas in the air. Besides, the high carbon content of LJ03 may relate to the attachment of carbon particles produced by incense-burning sacrifice.

\section{Blue}

The Raman peaks of the blue sample LJ04 are shown in Fig. 3. Although the two strong peaks of LJ04 at the position of $85 \mathrm{~cm}^{-1}$ and $402 \mathrm{~cm}^{-1}$ slightly skewed from 81 to $397 \mathrm{~cm}^{-1}$ of the azurite reference curve, respectively [13], the overall positions and intensity were consistent. It indicates that the blue substance in LJ04 is azurite. The contents of oxygen, carbon, and copper of SEM-EDS test are $44.8 \mathrm{wt} \%, 26.9 \mathrm{wt} \%$ and $6.5 \mathrm{wt} \%$, respectively, which confirms the Raman result. The silicon may come from the quartz in the base layer.

\section{Black}

The Raman curve of LJ05 showed two broad characteristic peaks at approximately 1320 and $1590 \mathrm{~cm}^{-1}$

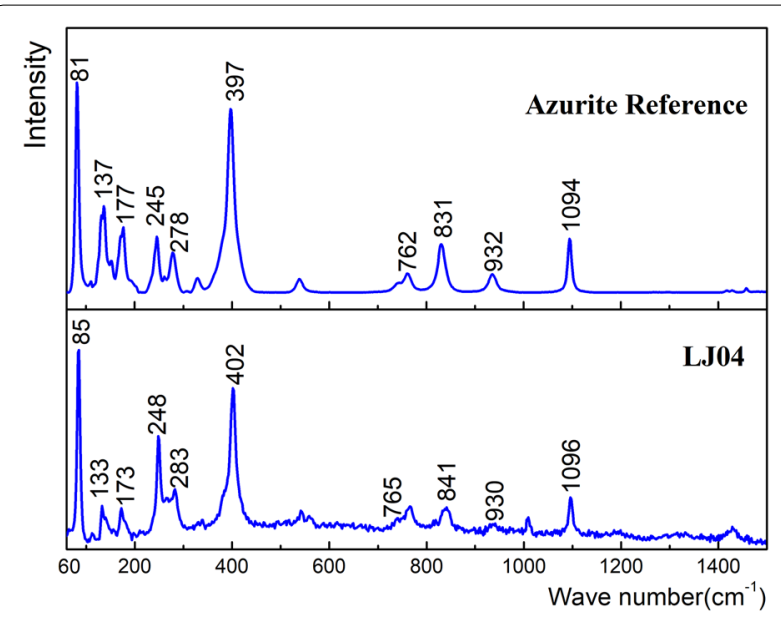

Fig. 3 Raman spectra of L04 and azurite reference

wavenumbers (see Fig. 4), which are the characteristic peaks of carbon black in graphite form [19]. These two peaks can also be used to compare the amorphous degree of carbon [20]. SEM-EDS results showed that the carbon content of LJ05 was $33.0 \mathrm{wt} \%$, and a variety of other elements were also detected, such as oxygen, calcium, lead and silicon. Carbon black is an incomplete combustion product of organic matter. It is the main component of Chinese ink, which is widely used as black colorant in Chinese ancient polychrome relics [21, 22].

\section{Red}

The Raman spectra of two red samples (LJ06 and LJ07) and cinnabar reference curve [14] are shown in Fig. 5. The respective strongest peaks of three curves at $253 \mathrm{~cm}^{-1}$ are almost identical, and the sub-strong peaks of them are also very similar. Moreover, sulfur and mercury were detected in both samples by SEM-EDS, which confirmed that the red pigment is cinnabar. The carbon contents of both samples were high, this can be related to the black substance found on the surface of the samples (Fig. 6). It can be speculated that the carbon element comes from the attachment of external carbon black particles on the surface of the sample, and the carbon black particles may come from the combustion of external organic sacrificial objects.

\section{Aureate}

The aureate samples were analyzed by SEM-EDS since metals are difficult to be detected by Raman. The mass percentages of the gold element in LJ08, LJ09 and LJ10 are $10.9 \%, 3.9 \%$ and $10.8 \%$, respectively. This indicates that the three aureate samples contain gold with low purity. The presence of lead in LJ10 is unexpected because it was not detected in the other aureate samples. 


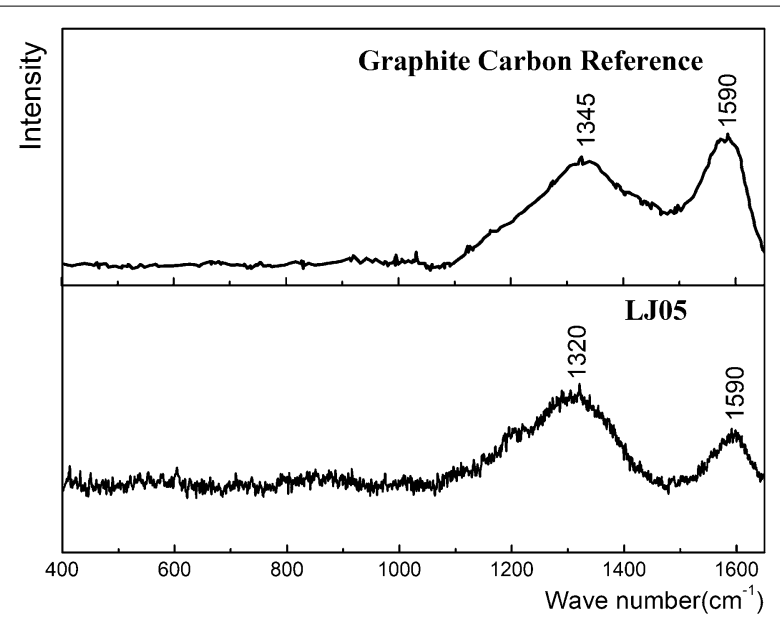

Fig. 4 Raman spectra of LJ05 and carbon black reference

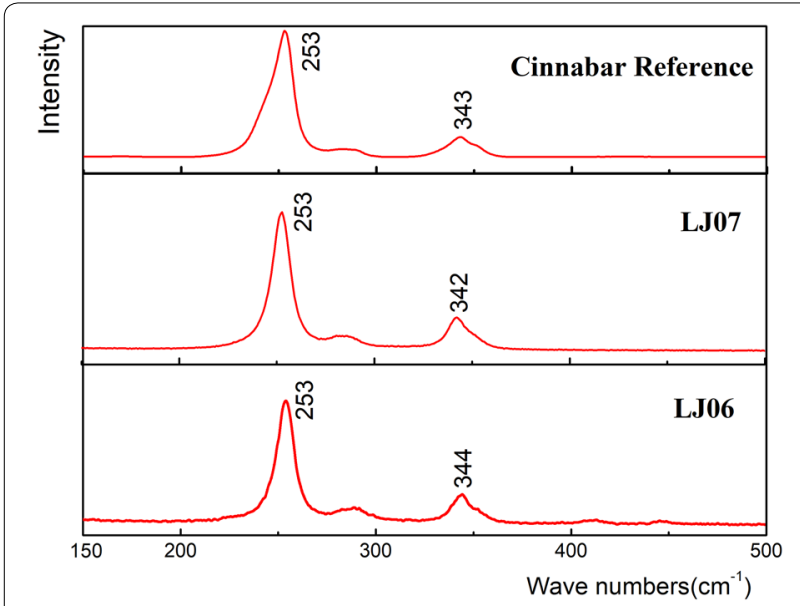

Fig. 5 Raman spectra of LJ06, LJ07 and cinnabar reference
It is believed to not belong to the original color layer. In order to clarify this question, we analyzed the elements in the base layer of LJ10. It is found that the mass percent of lead is $21.6 \%$ in the base layer, which can be inferred that the lead on the color layer of the LJ10 may be derived from its base layer.

Besides, the LiFen skill was used in the painting process of Longju temple. The craftsmen used the special powder paste to create raised lines on the original flat walls, and then stick the gold foil to the lines. This technique was mature when some Buddhist temples were built in the Ming dynasty [23], which made the mural look like a shallow relief.

Among the ten painted relics samples, atacamite was found in the three green paintings, azurite was the main composition of the blue pigment, carbon black was detected in the black sample, cinnabar was found in the two red paintings, and gold was found in three aureate samples. There have been a few tests for temple murals in the Ming dynasty in China. The only cases that have been consulted are the Qutan temple [24] and Yongdeng Tusi building [25]. These two sites are located in Northwest China, adjacent to Sichuan Province. Scholars detected azurite, atacamite and cinnabar in both sites, which is consistent with the results from Longju Temple. From this, it can be inferred that in the Buddhist murals in the central plains of China during the Ming dynasty, azurite was the main blue pigment, atacamite was the main green pigment, and cinnabar was the main red pigment, all of which were inorganic mineral pigments.

\section{Binder analysis}

The ELISA method was used to detect the binders of the samples. The results are shown in Table 3, in which the OD and SD mean optical density and standard deviation, respectively. The OD + 10SD values of the blank controls are set as the limits of detection (LOD). The LOD of egg
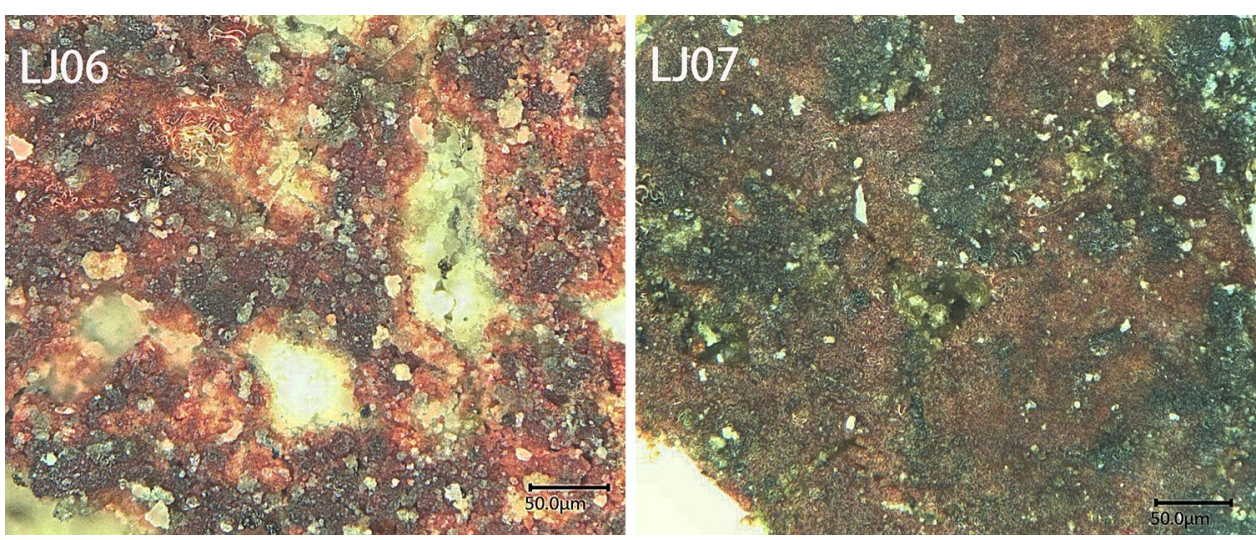

Fig. 6 Photographs of the adhesion of black particles on the surface of LJ06 and LJ07 
Table 3 ELISA results of samples from the Longju temple and positive controls

\begin{tabular}{llcc}
\hline Number & Egg white (OD \pm 10SD) & Animal glue (OD \pm 10SD) & Casein (OD \pm 10SD) \\
\hline Positive controls & $1.060 \pm 0.402$ & $0.483 \pm 0.062$ & $0.685 \pm 0.081$ \\
L01 & $0.118 \pm 0.197$ & $0.210 \pm 0.087$ & $0.021 \pm 0.017$ \\
L02 & $0.067 \pm 0.057$ & $0.100 \pm 0.055$ & $0.210 \pm 0.046$ \\
L03 & $0.101 \pm 0.127$ & $0.131 \pm 0.087$ & $0.033 \pm 0.061$ \\
L04 & $0.212 \pm 0.176$ & $0.129 \pm 0.090$ & $0.015 \pm 0.032$ \\
L05 & $0.047 \pm 0.052$ & $0.083 \pm 0.050$ & $0.037 \pm 0.035$ \\
L06 & $0.046 \pm 0.032$ & $0.106 \pm 0.042$ & $0.034 \pm 0.015$ \\
L07 & $0.142 \pm 0.087$ & $0.170 \pm 0.030$ & $0.032 \pm 0.035$ \\
L08 & $0.048 \pm 0.046$ & $0.399 \pm 0.093$ & $0.029 \pm 0.045$ \\
L09 & $0.060 \pm 0.085$ & $0.338 \pm 0.153$ & $0.027 \pm 0.032$ \\
L10 & $0.056 \pm 0.042$ & & $0.028 \pm 0.081$ \\
\hline
\end{tabular}

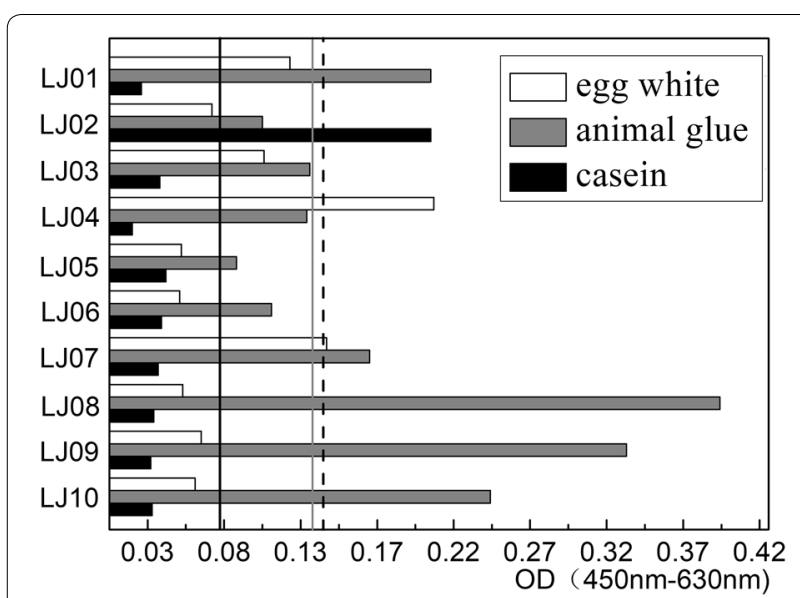

Fig. 7 Compared graph of OD value and the limit of detection of ten samples (the minimum detection thresholds of egg white, animal glue and casein are $0.137,0.133$ and 0.072 )

white, animal glue and casein are 0.137, 0.133 and 0.072 , respectively. If the OD value of the sample is greater than the related LOD value, the corresponding antigen exists in the sample.

The OD value of samples compared with the LOD value is shown in Fig. 7. The white, grey and black columns represent the OD values of egg white, animal glue and casein, respectively (without adding the SD values). The black dashed line, grey line and black line represent the LOD value of egg white, animal glue and casein, respectively. The OD values of LJ04 and LJ07 exceed the LOD value of egg white, suggesting the existence of egg white in these samples. The OD values of LJ01 and LJ07-LJ10 are higher than the corresponding LOD value of animal glue. It illustrated that half of the samples, including all aureate samples, contain animal glue. The OD value of LJ02 exceeded the LOD of casein, indicating the existence of casein in this sample. No binder was detected in
LJ03, LJ05, and LJ06 from the ELISA results. There is a minimum antigen concentration in the ELISA analysis. If the concentration of proteinaceous binders in samples was below this concentration, the positive results may not be captured, it does not necessarily indicate the absence of binding media.

Animal glue is the most widely used binding media in ancient polychrome relics, researchers had found it in Dunhuang murals [26], Kizil Grottoes [27], Qin Terracotta Army [28] and other cultural relics. The results of the Longju temple also accord with this inference since half of the samples contain animal glue. Two samples contain egg white, in which LJ07 contains both egg white and animal glue. Egg white has sterilization and waterproofing functions [29], which can make up for the shortcomings of animal glue (e.g., lack of water resistance and easy deterioration) and greatly increase the stability of polychrome relics. Moreover, casein was detected in sample LJ02, which indicated that dairy products were used as a binder. However, casein was rarely detected as binding media in the central plains of China. As we all know that dairy is one of the daily consumptions of Tibetans, and Sichuan is located in the border between Tibet and Han areas. It is speculated that the production of Longju temple murals was influenced by religion to some extent.

\section{Conclusions}

In order to identify pigments and binding media from the Longju temple of the Ming dynasty, ten polychromic samples were studied using a comprehensive method. The results showed that the pigments of atacamite, azurite, carbon black, cinnabar and gold were used in the Ming dynasty. These paintings may be affected by various factors, including the migration of calcium from the base layer and the adherence of external carbon particles. Animal glue, egg white, and casein were detected using 
ELISA methods. One of the red samples contained animal glue and egg white. Casein was found in the green sample. This study not only offered essential data for the follow-up protection and repair projects but also provided a reference to further explore the cotemporaneous polychrome relics of Buddhist temples.

\section{Abbreviations}

SEM-EDS: scanning electron microscopy-energy disperse spectrometer; ELISA: enzyme-linked immunosorbent assay; OD: optical density; SD: standard deviation.

\section{Acknowledgements}

The authors thank the China Silk Museum for access to Raman and SEM-EDS equipment and the colleagues who assisted during the work. We also thank Dr. Li of Zhejiang University for his kindly help.

\section{Authors' contributions}

EC and BZ designed the research project and wrote this publication; EC performed the whole procedure of experimental analysis; $\mathrm{FZ}$ and $\mathrm{CW}$ was responsible for early investigation and field sampling and provided valuable comments on the manuscript. All authors read and approved the final manuscript.

\section{Funding}

This project was funded by The Conservation Science and Technology Project of Zhejiang Provincial Administration of Cultural Heritage (2017).

\section{Availability of data and materials}

Available upon request by the authors.

\section{Ethics approval and consent to participate}

This article does not contain any studies with human participants or animals performed by any of the authors.

\section{Consent for publication}

The consent for the publication of details and images in the manuscript are obtained from all participants.

\section{Competing interests}

The authors declare that they have no competing interests.

\section{Author details}

${ }^{1}$ Department of Cultural Heritage and Museology, Zhejiang University, Hangzhou 310028, Zhejiang, People's Republic of China. ${ }^{2}$ Department of Chemistry, Zhejiang University, Hangzhou 310027, Zhejiang, People's Republic of China. ${ }^{3}$ Cultural Relics and Archaeology Institute of Sichuan, Chendu 610000,

Sichuan, People's Republic of China.

Received: 29 December 2018 Accepted: 25 June 2019

Published online: 02 July 2019

\section{References}

1. Cao D. Discussion on Sichuan frescoes. SC Cult Relic. 1996:03:21-2.

2. Yao J. An analysis on changes of architectural structure and styles during the Ming and Qing Periods in Sichuan. Archaeol Cult Relic. 2017;06:70-81.

3. Liang SC. Complete works of Liang Sicheng, vol. 3. 1st ed. Beijing: China Architecture \& Building Press; 2001.

4. Kock LD, De Waal D. Raman analysis of ancient pigments on a tile from the Citadel of Algiers. Spectrochim Acta Pt A-Mol Bio. 2009;71(4):1348-54.

5. Cosano D, Mateos LD, Jiménez-Sanchidrián C, Ruiz JR. Identification by Raman microspectroscopy of pigments in seated statues found in the Torreparedones Roman archaeological site (Baena, Spain). Microchem J. 2017;130:191-7
6. Vincenza C, Barbara F Giacomo F Giuliana G, Francesco LRM, Maurizio L, et al. Multi-analytical study of Roman frescoes from Villa dei Quintili (Rome, Italy). J Archaeol Sci. 2018:21:422-32.

7. Linn R. Layered pigments and painting technology of the Roman wall paintings of Caesarea Maritima. J Archaeol Sci. 2017:11:774-81.

8. Marić-Stojanović M, Bajuk-Bogdanović D, Uskoković-Marković S, Holclajtner-Antunović I. Spectroscopic analysis of XIV century wall paintings from Patriarchate of Peć Monastery, Serbia. Spectrochim Acta Pt A Mol Bio. 2018;191:469-77.

9. Palmieri M, Vagnini M, Pitzurra L, Brunetti BG, Cartechini L. Identification of animal glue and hen-egg yolk in paintings by use of enzyme-linked immunosorbent assay (ELISA). Anal Bioanal Chem. 2013;405(19):6365-71.

10. Liu L, Shen W, Zhang B, Ma Q. Microchemical study of pigments and binders in polychrome relics from Maiji Mountain Grottoes in Northwestern China. Microsc Microanal. 2016;22(4):845-56.

11. Hu W, Zhang H, Zhang B. Identification of organic binders in ancient Chinese paintings by immunological techniques. Microsc Microanal. 2015;21(5):1278-87.

12. RRUFF database. Berlin, Germany. 2015. http://rruff.info/R050098/displ ay=default/. Accessed 4 Nov 2018.

13. RRUFF database. Berlin, Germany. 2015. http://rruff.info/R050638/displ ay=default/. Accessed 11 Nov 2018.

14. RRUFF database. Berlin, Germany. 2015. http://rruff.info/R070532/displ ay=default/. Accessed 11 Nov 2018.

15. Liu LY, Shen W, Zhang B, Han YC. Determination of proteinaceous binders for polychrome relics of Xumi Mountain Grottoes by using enzymelinked immunosorbent assay and immunofluorescence microscopy. Int J Conserv Sci. 2016;7(1):3-14

16. Lei Y. Copper trihydroxychlorides as pigments in China. Stud Conserv. 2012;57(2):106-11.

17. Wang JY, Wang JC. The application and origin of copper trihydroxychlorides in Dunhuang grottoes. Dunhuang Res. 2002;74(04):23-8.

18. Bai $K, \operatorname{Han} Z$. The discovery and geological significance of parachloride copper deposit in Kanggurtag gold deposit. Xinjiang. Northwestern Geol. 2007:02:114-7.

19. Mateos LD, Esquivel D, Cosano D, Jiménez-Sanchidrián C, Ruiz JR. Micro-Raman analysis of mortars and wall paintings in the Roman villa of Fuente Alamo (Puente Genil, Spain) and identification of the application technique. Actuators A Phys. 2018;281:15-23.

20. Jawhari T, Roid A, Casado J. Raman spectroscopic characterization of some commercially available carbon black materials. Carbon. 1995:33(11):1561-5.

21. Liu Z, Han Y, Han L, Cheng Y, Ma Y, Fang L. Micro-Raman analysis of the pigments on painted pottery figurines from two tombs of the Northern Wei dynasty in Luoyang. Spectrochim Acta Pt A Mol Bio. 2013;109:42-6.

22. Si Y, Jiang HE, Wang $B, H e ~ Q, H u Y$, Yang $Y$, et al. Raman microspectroscopic analysis of polychrome wooden artifact from the Astana tomb of the Tang Dynasty, Xinjiang, China. Spectrosc Spect Anal. 2013;33(10):2607-11.

23. Xie S. Analysis of the pigment and artistic styles of Fahai Temple. Art. 2017;06:140-1

24. Chen G, Yu Z, Chai B, Cui Q, Zhang W, Wang X, et al. On the application of nondestructive in situ analysis on wall paintings of the Lu Tusi Yamen building in Yongdeng County. Dunhuang Res. 2018;169(03):28-37.

25. Wang JT, Li J, Tang J, Xu Z. Study on mural pigment of Qutan temple in Qinghai province. Sci Conserv Archaeol. 1993:5(02):23-35.

26. Li S. Quantitative analysis of the binding medium of Dunhuang frescoes. Dunhuang Res. 1995;3:29-46.

27. Su B, Tetuo S, Hu Z, Li Z. HPLC analysis of binding medium of pigments of wall-painting at Kizil grottoes. Dunhuang Res. 2005;92(4):57-62.

28. Wei SY, Ma Q, Schreiner M. Scientific investigation of the paint and adhesive materials used in the Western Han dynasty polychromy terracotta army, Qingzhou, China. J Archaeol Sci. 2012;39:1628-33.

29. Cunningham FE, Proctor VA, Goetsch SJ. Egg-white lysozyme as a food preservative: an overview. World Poult Sci J. 1991:47(2):141-63.

\section{Publisher's Note}

Springer Nature remains neutral with regard to jurisdictional claims in published maps and institutional affiliations. 